\title{
BMJ Global Health Intimate partner violence among women with and without disabilities: a pooled analysis of baseline data from seven violence-prevention programmes
}

\author{
Esnat Chirwa, ${ }^{1,2}$ Rachel Jewkes, ${ }^{1}$ Ingrid Van Der Heijden, ${ }^{1}$ Kristin Dunkle (D) ${ }^{1}$
}

To cite: Chirwa E, Jewkes R, Van Der Heijden I, et al. Intimate partner violence among women with and without disabilities: a pooled analysis of baseline data from seven violence-prevention programmes. BMJ Global Health 2020:5:e002156. doi:10.1136/ bmjgh-2019-002156

Handling editor Sanne Peters

- Additional material is published online only. To view please visit the journal online (http://dx.doi.org/10.1136/ bmjgh-2019-002156).

Received 10 November 2019 Revised 12 May 2020 Accepted 15 May 2020

A) Check for updates

(c) Author(s) (or their employer(s)) 2020. Re-use permitted under CC BY-NC. No commercial re-use. See rights and permissions. Published by BMJ.

${ }^{1}$ Gender and Health Research Unit, South African Medical Research Council, Tygerberg, South Africa

${ }^{2}$ School of Public Health, University of the Witwatersrand, Johannesburg, South Africa

Correspondence to

Dr Kristin Dunkle;

kristin.dunkle@mrc.ac.za

\section{ABSTRACT}

Introduction Intimate partner violence (IPV) is a serious public health and human rights violation which impacts approximately one in three women worldwide. Some existing evidence suggests that women with disabilities are at higher risk of IPV, but is largely limited in geographical scope to the Global North, and comparison across settings has been hampered by inconsistent measurement of both IPV and disability.

Methods Pooled analysis of baseline data from 8549 adult women participating in seven IPV prevention studies in five countries across Africa and Asia that used collaborative, comparative measurement strategies to assess both disability and IPV.

Results After adjusting for age, women with disabilities were more likely to experience past 12-month physical IPV (adjusted OR (aOR)=1.79; 95\% Cl 1.49 to 2.17), sexual IPV (aOR=1.98; 95\% Cl 1.36 to 2.89), emotional IPV (aOR=1.84; $95 \% \mathrm{Cl} 1.49$ to 2.27$)$ and economic IPV (a0R=1.66; $95 \% \mathrm{Cl} 1.45$ to 1.89), with an overall association between disability and past 12-month physical/ sexual IPV of aOR=1.93 (95\% $\mathrm{Cl} 1.52$ to 2.46$)$. Compared to women without disability, women with moderate and severe disability showed a trend of increasing risk of IPV in the past 12 months for each of physical, sexual, emotional and economic IPV. Overall, both women with moderate disability (aOR=1.86, 95\% $\mathrm{Cl} 1.57$ to 2.21) and women with severe disability (aOR=2.63; $95 \% \mathrm{Cl} 1.95$ to 3.55 ) were significantly more likely to experience any form of IPV when compared with women without disability.

Conclusion Women with disabilities are at increased risk of past-year IPV compared to women without disabilities across a range of settings in the Global South, and the risk of IPV increases with increasing severity of disability. IPV prevention and response efforts in these settings must find ways to include and address the needs of women with disabilities, including increased outreach and improved accessibility of programmes.

\section{INTRODUCTION}

Intimate partner violence (IPV) is the most common form of violence experienced by women and girls worldwide; at least one in three women worldwide report experiencing

\section{Key questions}

\section{What is already known?}

- Intimate partner violence (IPV) is a serious health and human rights violation which impacts approximately one in three women worldwide.

- Some studies largely from the Global North have suggested that women with disabilities are at higher risk of IPV.

What are the new findings?

- Pooled estimates from seven studies in five African and Asian countries show that women with disabilities are nearly twice as likely to report recent IPV in these settings.

- In addition, the likelihood of reporting recent IPV increases with increasing severity of disability.

- These findings apply to all of physical, sexual, emotional and economic IPV, as well combined measures of IPV.

\section{What do the new findings imply?}

- IPV prevention and response efforts in the Global South should find ways to include and address the needs of women with disabilities, including increased outreach and improving accessibility of programmes.

- Programmes for people with disabilities should actively seek to address risk of IPV.

physical and/or sexual IPV during their lifetime. ${ }^{1}$ Globally, IPV leads to physical and mental health problems, including pain, depression, post-traumatic stress disorder, increased substance abuse, negative sexual and reproductive health outcomes, injuries and death. ${ }^{2-5}$ For the $15 \%$ of women worldwide with existing disabilities, ${ }^{6}$ risk of IPV may be increased by limitations in self-protection resulting from their disabilities, as well as increased social marginalisation. ${ }^{78}$ Systematic social marginalisation, stigma and discrimination may also indirectly increase risk of IPV among women with disabilities through 
increasing the likelihood and severity of other risk factors for IPV, such as poverty and lack of education. ${ }^{910}$

The majority of existing research on the association between disability and IPV comes from the Global North, where evidence, while limited, consistently shows that women with disabilities are at greater risk of IPV than either women without disabilities or men with disabilities. ${ }^{11-18}$ A 2012 systematic review and meta-analysis of past 12 months' experience of violence among female and male adults with disabilities identified only five studies that looked at IPV. ${ }^{11}$ All were from the USA or Canada and three included only data on mental illness in non-representative samples, from which the authors estimated a pooled OR of 1.78 (95\% CI 1.42 to 2.22) for recent IPV among 574 adults with mental illness. ${ }^{11}$ Cross-sectional analysis of larger and somewhat more representative datasets from the USA, ${ }^{14-16}{ }^{18}$ Germany $^{13}$ and Australia ${ }^{19}$ also found increased risk of IPV ${ }^{13-16} 19$ and non-partner sexual violence ${ }^{161819}$ among women with disabilities. Importantly, the National Epidemiologic Survey on Alcohol and Related Conditions in the USA found that past 12 months' IPV at wave 2 data collection was higher among women who had reported physical $(\mathrm{OR}=1.22)$ and mental $(\mathrm{OR}=1.67)$ health impairments at Wave 1 threeyears earlier, strongly suggesting that disability can increase vulnerability to IPV over time. ${ }^{12}$

While these findings strongly suggest that disability should be regarded as an important risk factor for IPV in at least some countries in the Global North, there have been limited attempts to date to synthesise evidence about links between disability and IPV across settings. Most importantly, despite urgent calls in the literature, ${ }^{20}$ there has been very little research on disability and IPV in the Global South. Given that $80 \%$ of all people with disabilities live in the Global South, ${ }^{6}$ this is a significant evidence gap. Women with disabilities in the Global South experience greater economic disadvantage, social isolation and barriers to accessing limited resources than do women resource-rich settings, ${ }^{21}$ potentially increasing their vulnerability to entering and remaining in abusive relationships. Most research on disability and IPV in the Global South has been small-scale, with limited ability to compare to women without disabilities or compare across settings. ${ }^{22-27}$ In addition to the geographical limitations of detailed examinations of the link between disability and IPV, few studies disaggregate severity of disabilities included in their samples. Across the board, there remain challenges in estimating IPV prevalence among disabled women due to inconsistent strategies for measuring both disability and experiences of violence, which further undermines any ability to compare and synthesise findings on IPV against women with disabilities across settings. ${ }^{20}$

To address these gaps, we conducted a pooled analysis of baseline enrolment data from seven IPV prevention studies conducted in five countries under the aegis of the UKaid-funded What Works to Address Violence Against Women and Girls? Global Programme (What Works). A main goal of What Works was to advance the evidence base regarding effective prevention of IPV the Global South, and to that end, What Works supported impact evaluations for a range of IPV prevention programmes in sub-Saharan Africa and Asia. As projects conducted within the framework of a cooperative consortium, we were able to coordinate strategies for the measurement of physical and sexual IPV and of disability, and thus achieve a greater degree of comparability across settings than has previously been possible. In total, the pooledanalysis presented here synthesises the baseline enrolment data from 8549 adult women with and without disabilities collected from seven studies conducted in five countries in sub-Saharan Africa (Ghana, Rwanda and South Africa) and Asia (Nepal and Afghanistan). We first examine the odds of women' reporting IPV in the past 12 months associated with any disability, and then the odds of past 12-month IPV associated with increasing severity of disability. We hypothesised that women with disabilities would be more likely to report recent experience of IPV than women without disabilities, and that the likelihood of reporting recent IPV would increase with increasing severity of disability.

\section{METHODS}

The location, study design, number of women recruited, age range, sampling strategy and eligibility criteria for each study included in this pooled analysis are presented in table 1, with references to sources that describe each study in full detail. The data available for analysis were collected in studies that were primarily intended as evaluations of intervention effectiveness. However, for the purposes of this pooled analysis we have used only data collected at baseline (prior to intervention delivery), so we do not here describe the interventions themselves beyond their target populations. We do note that some of these studies' participants were volunteers enrolled in cohorts, while some were interviewed in cross-sectional surveys of populations within communities.

\section{Key measures}

Disability

All studies included elements from the Washington Group Short Set (WG-SS) of Questions on Disability, which has six possible questions. ${ }^{28}$ The questions ask participants to self report their levels of difficulty in up to six functional domains: vision, hearing, movement, memory and concentration, self-care and communication. As an example, the question on vision asks, 'Do you have difficulty seeing even if wearing glasses?' with answer choices scored as $1=$ No difficulty; $2=Y e s$, some difficulty; 3=Yes, a lot of difficulty; 4=Cannot do at all. All studies included here asked questions on vision, hearing, movement and cognition, and all but Rwandan datasets used the question on communication. Two studies further included the question on self care: the Women's Empowerment Program (Afghanistan) and Sammanit 
Table 1 Studies used as data sources for women included in the pooled analysis

\begin{tabular}{|c|c|c|c|c|c|c|}
\hline Programme & Country & Type of study & $\mathrm{N} †$ & $\begin{array}{l}\text { Women's age } \\
\text { range }\end{array}$ & $\begin{array}{l}\text { Sampling or } \\
\text { recruitment } \\
\text { strategy }\end{array}$ & $\begin{array}{l}\text { Eligibility criteria for inclusion in } \\
\text { baseline interviews }\end{array}$ \\
\hline $\begin{array}{l}\text { Evaluation of Sammanit } \\
\text { Jeevan }^{35}\end{array}$ & Nepal & $\begin{array}{l}\text { Recruitment of families } \\
\text { from six villages, no } \\
\text { randomisation }\end{array}$ & 200 & $18+$ & Volunteer & $\begin{array}{l}\text { Families with a married young } \\
\text { woman. } \\
\text { Two women per family were } \\
\text { enrolled into the programme, of } \\
\text { different generations, if available. }\end{array}$ \\
\hline $\begin{array}{l}\text { Evaluation of Stepping } \\
\text { Stones/Creating Futures } \\
36\end{array}$ & South Africa & $\begin{array}{l}\text { Randomisation of } 34 \\
\text { clusters }\end{array}$ & 680 & $18-30$ & Volunteer & $\begin{array}{l}\text { Young women normally resident in } \\
\text { the informal settlement. } \\
\text { Not in full time work or education. }\end{array}$ \\
\hline $\begin{array}{l}\text { Evaluation of the } \\
\text { Women's Empowerment } \\
\text { Program }{ }^{37}\end{array}$ & Afghanistan & $\begin{array}{l}\text { Individual level } \\
\text { randomisation within } \\
\text { six study villages }\end{array}$ & 933 & $18-49$ & Volunteer & $\begin{array}{l}\text { Residence in intervention or control } \\
\text { community. } \\
\text { Only one woman per household. } \\
\text { Economically vulnerable. }\end{array}$ \\
\hline $\begin{array}{l}\text { Evaluation of the } \\
\text { Indashyikirwa couples' } \\
\text { intervention* } \\
3839\end{array}$ & Rwanda & $\begin{array}{l}\text { Randomisation of } \\
28 \text { clusters (sectors) } \\
\text { across seven districts }\end{array}$ & 1600 & $18-50$ & Volunteer & $\begin{array}{l}\text { Residence in community for at least } \\
6 \text { months prior to survey. } \\
\text { Married or cohabitating for at least } \\
6 \text { months prior to survey. } \\
\text { Recruited from voluntary savings } \\
\text { and loan associations. }\end{array}$ \\
\hline $\begin{array}{l}\text { Evaluation of the Rural } \\
\text { Response System }\end{array}$ & Ghana & $\begin{array}{l}\text { Randomisation of } 4 \\
\text { districts with data } \\
\text { collected from } 38 \\
\text { clusters }\end{array}$ & 1877 & $18-50$ & $\begin{array}{l}\text { Population-based } \\
\text { survey }\end{array}$ & $\begin{array}{l}\text { Residence in intervention or control } \\
\text { community. }\end{array}$ \\
\hline $\begin{array}{l}\text { Evaluation of Change } \\
\text { Starts at Home }\end{array}$ & Nepal & $\begin{array}{l}\text { Randomisation of } 36 \\
\text { clusters across three } \\
\text { districts }\end{array}$ & 1800 & $18-49$ & $\begin{array}{l}\text { Population-based } \\
\text { survey }\end{array}$ & $\begin{array}{l}\text { Women living with their partner } \\
\text { in a study intervention or control } \\
\text { community. }\end{array}$ \\
\hline $\begin{array}{l}\text { Evaluation of the } \\
\text { Indashyikirwa } \\
\text { community intervention* } \\
3839\end{array}$ & Rwanda & $\begin{array}{l}\text { Randomisation of } \\
28 \text { clusters (sectors) } \\
\text { across seven districts }\end{array}$ & 1399 & $18-50$ & $\begin{array}{l}\text { Household- } \\
\text { based survey of } \\
\text { residents who } \\
\text { were not direct } \\
\text { programme } \\
\text { participants }\end{array}$ & $\begin{array}{l}\text { Residence in community for at least } \\
6 \text { months prior to survey. } \\
\text { Married or cohabitating for at least } \\
6 \text { months prior to survey. } \\
\text { Not enrolled in the couples' cohort } \\
\text { of the Indashyikirwa study. }\end{array}$ \\
\hline
\end{tabular}

${ }^{*}$ The Indashyikirwa impact evaluation study included both a cohort of couples recruited from voluntary savings and loan associations and householdbased surveys of residents of intervention or control areas.

†Number of women who provided disability and IPV data and are therefore included in this analysis.

IPV, intimate partner violence.

Jeevan (Nepal). As recommended by the authors of the measure, ${ }^{29}$ participants were initially classified as having a disability if they replied 'Yes, a lot of difficulty' or 'Cannot do at all' regarding one or more functional domains. To assess the relationship between severity of disability and IPV experience, we created second disability variable with three mutually exclusive categories: no disability, moderate disability and severe disability. Any participant who responded 'No difficulty' to all the domains was classified as having no disability, while a participant who replied 'Yes, some difficulty' in at least one domain but had zero 'Yes, a lot of difficulty' or 'Cannot do at all' answers was classified as having moderate disability. A participant who answered 'Yes, a lot of difficulty' or 'Cannot do at all' to any of the domains was classified as having severe disability.

\section{Intimate partner violence}

IPV was defined in most studies as occurring with a current or ex-husband or boyfriend. In some settings, there was common dating or cohabitation outside marriage, while in others having a boyfriend would have been both socially forbidden and extremely problematic for women. Specific question wording was therefore tailored to the setting to ensure acceptability, and no reference to 'boyfriend' was made in countries where dating was socially unacceptable or dangerous for women, such as Afghanistan or where women were recruited into studies in their marital family. For similar reasons, no study included women with female, non-binary or third gender partners. All studies used standardised items from the WHO Violence Against Women Instrument to measure experience of physical and/or sexual IPV experienced by women in the 12 months preceding the baseline data collection. ${ }^{30}$ This measure uses five items for physical IPV: In the past 12 months, how many times has [your current or previous partner-study specific language] (1) slapped you or thrown something at you which could hurt you; (2) pushed or shoved you; (3) hit you with a fist or with something else which could hurt you; (4) kicked, dragged, beaten, choked or burnt you; (5) threatened to use, or actually used, a gun, knife or other weapon against you? Afghanistan did not include any items on sexual 
IPV as local collaborators advised that it was particularly likely to have been unacceptable for some participants. All other studies included the same three items on sexual IPV: In the past 12 months, how many times has [your current or previous partner-study specific language] (1) physically forced you to have sex with him when you did not want to; (2) used threats or intimidation to make you have sex when you did not want to; (3) used physical force or threats to make you do something else sexual that you did not want to do? Answer choices for all physical and sexual IPV questions were 'Never', 'Once', 'A few times' or 'Many times', Questions on emotional and economic IPV used the same question format and answer choices, but with details tailored to each study context. The number of items used to measure emotional IPV ranged from 4 to 7 while the number of items used to measure economic violence ranged from 1 to 4 . For each type of IPV, a woman was classified as having experienced violence in the 12 months prior to baseline if they responded positively to any of the items measuring that form of violence (once, few times or many times). A variable to measure a woman's experience of sexual and/or physical IPV was derived from their experience of these two forms of IPV and an overall experience of IPV was derived from all the types of IPV measured.

\section{Other measures}

All studies assessed numerical age of participants. Other socio-demographic questions were tailored to the context and target populations of the individual projects. To enable some comparisons using these different measures, we derived variables based on within-study distributions. For education level, we derived a dichotomous measure using each study's median as a cut-off. Household food insecurity was measured using varying numbers of items with similar scoring across settings; we therefore used the mean score on these items within each study a proxy measure for comparing household food insecurity. We did not attempt any summary measure of employment as the measurement and meaning of this varied too much across settings.

\section{Data analysis}

Analysis was restricted to women who reported at least one intimate partner in the 12 months preceding the baseline data collection and completed the disability questions. Participants who responded to at least one of the disability questions were included in the analysis. Participants who did not respond to any of the disability or IPV questions were excluded from the analysis. Descriptive statistics (frequencies and percentages) were used to summarise characteristics of participants within each study and in the pooled analysis. Within-study and pooled estimates took into account any clustering with each study's sampling procedures.

All pooled estimates were weighted according to study sample size. We used forest plots (see figure 1 ), $\mathrm{I}^{2}$ and Cochran's Q statistics to assess consistency of outcomes across the studies. Due to varying levels of heterogeneity across the studies for the different types of IPV (see online supplementary table S1), we opted for mixed effects models to estimate overall effects. We thus performed a one-stage Individual Patient Data meta-analysis using mixed effects logistic regression models to account for within- and between- study variances (heterogeneity) across studies. ${ }^{31}$ We used a mixed effect logistic regression model that took into account the hierarchy of the data (grouping participants within study). Apart from disability as the main exposure, age of participants was included in the model as a fixed effect. Study specific estimates and forest plots were derived as part of the postestimation model to the mixed effects logistic regression. The post-estimation model included study centred age as a fixed effect. To assess possible bias resulting from different recruitment strategies (four volunteer recruited vs three household based surveys), we repeated all analyses separately for these two groups of studies. We used same procedure as above to assess whether the risk of experiencing IPV increased with severity of disability. A mixed effects logistic regression model was used to derive estimates of odds ratios for the moderate and severe level of disability. The model included the study and age of participants. As additional sensitivity analyses (presented as supplementary tables), we re-ran the mixed effects logistic regression models with adjustment for our derived variables of within-study median education and mean food insecurity scores. All analyses were done in Stata V.16.

\section{Ethical issues}

All participants in all studies provided informed consent; details are available in the sources referenced in table 1.

\section{Indirect patient and public involvement}

It was not relevant to directly include patient and public involvement in this analysis, but the underlying individual projects were conducted with varying degrees of patient and public involvement and What Works' broader research uptake strategy includes widespread engagement with key stakeholder groups including women's rights organisations and disabled people's organisations.

\section{RESULTS \\ Socio-demographics, prevalence of disability and past 12 months' IPV}

Pooled data from 8549 women across the seven studies were used in the analysis. This number excluded all women who had not been in an intimate relationship in the 12 months preceding the baseline data collection, or who failed to provide usable data on disability or IPV. The percentage of participants excluded in each study due to missing IPV or disability responses ranged from $0 \%$ to $0.2 \%$. Table 2 shows socio-demographics, prevalence of disability and prevalence of violence among participants in all studies. The average age of the women across all studies was 32 years. Most of the women were 

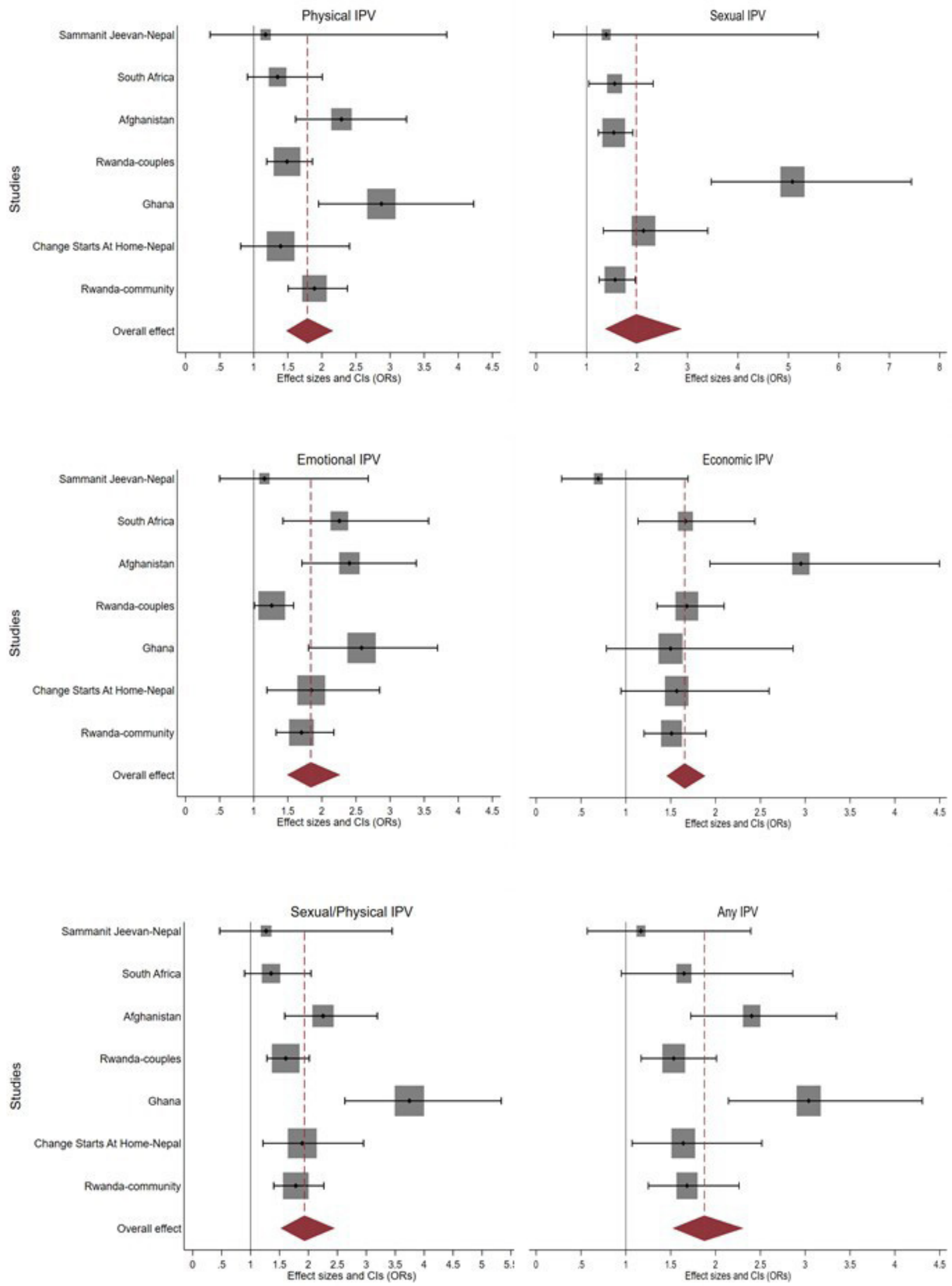

Figure 1 Forest plots showing individual study age-adjusted ORs and pooled ORs for experience of different types of IPV in the past 12 months among women with and without disabilities in baseline data from 7 IPV prevention studies in five counties. IPV, intimate partner violence. 


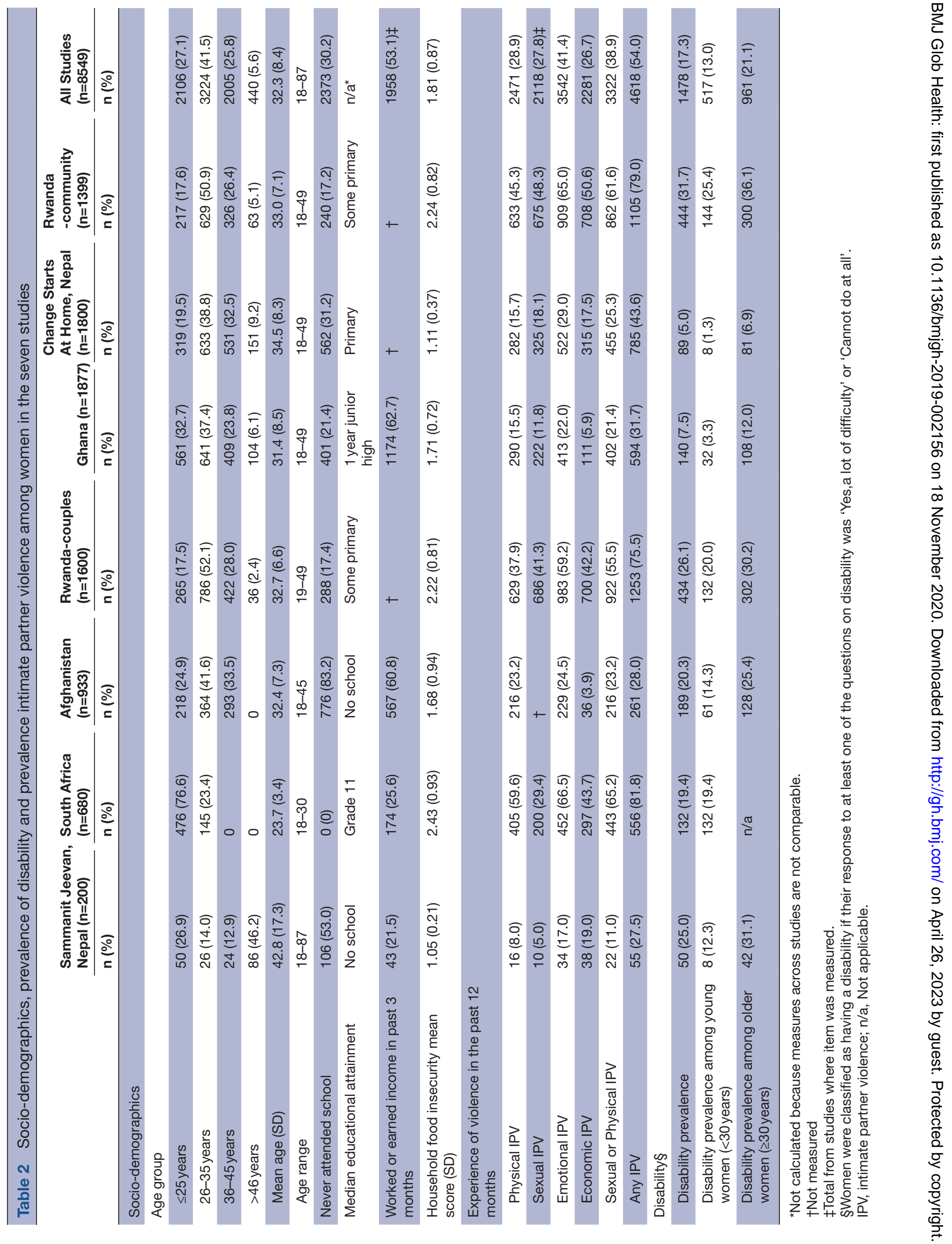


younger, with $47 \%$ aged 30 years or younger, and a total of $66.5 \%$ aged up to 35 years. However, there were some much older women $(<1 \%$ were 50 years or older). The age range was widest in the family-centred study in Nepal as the women enrolled included daughter-in-law and mother-in-law pairs from the same household, with the oldest women being 87 . Overall, $30.2 \%$ of the women had never attended any school, and in only one study (South Africa) did all women have some schooling. In Afghanistan, by contrast, the great majority of women had no schooling. Just over half 53.1\% (1958/3686) of those enrolled in studies which collected employment data said that they had worked or earned some income in the 3 months preceding the baseline study.

The overall prevalence of disability among the 8549 women was $17.3 \%$, with study specific prevalence ranging from $5 \%$ to $31.7 \%$. About one in five $(21.1 \%)$ women above 30 years of age had some form of disability with study specific prevalence in this age group ranging from $6.9 \%$ to $36.1 \%$. Disability prevalence among younger women was $13 \%$, with study specific prevalence ranging from $1.3 \%$ to $25.4 \%$.

More than a quarter $(28.9 \%)$ of the women in the seven studies experienced physical violence from male intimate partners in the 12 months preceding the baseline studies, with study specific prevalence ranging from $8 \%$ to $59.6 \%$ (table 3 ). Close to a third $(27.8 \%$ ) of the women had experienced sexual IPV, with study-specific prevalence ranging from $5 \%$ to $48.3 \%$. The overall prevalence for emotional IPV and economic IPV experience was $41.4 \%$ and $26.7 \%$, respectively, and just over half $(54 \%)$ of the women had experienced some form of IPV (physical, sexual, emotional or economic), with study specific prevalence of IPV ranging from $27.5 \%$ to $81.8 \%$. Three in four women who had experienced economic IPV also experienced emotional IPV, and about 38.9\% women experienced either sexual or physical IPV.

\section{Relationship between disability and violence}

Table 3 shows the percentage of women with and without disability who experienced different forms of violence in the 12 months preceding the baseline data collection across the seven studies. There was a significant association between disability and all forms of IPV. The overall prevalence of physical IPV among women with disability was $44 \%$ compared to $26 \%$ among women without disability. Almost half $(45.6 \%)$ of the women with disability experienced sexual IPV compared to $24.2 \%$ of women without disability. Over half $(59.3 \%)$ of the women with disability experienced emotional IPV compared to $37.7 \%$ among women with no disability. Similarly, $42.6 \%$ vs $23.4 \%$ of women with and without a disability respectively reported economic IPV. Women with a disability were significantly more likely to report recent IPV from a male partner, with little difference in magnitude seen by type of violence: physical IPV aOR=1.79 (95\% CI 1.48 to 2.17), sexual IPV aOR $=1.98$ (95\% CI 1.36 to 2.89 ), emotional IPV aOR=1.84 (95\% CI 1.49 to 2.27) and economic IPV
$\mathrm{aOR}=1.66$ (95\% CI 1.45 to 1.89$)$. Overall, women with disability were nearly twice as likely to report past 12 months' sexual and/or physical IPV (aOR=1.93; 95\% CI 1.52 to 2.46 ) as women without disabilities. Women with disability are also about twice as likely to experience at least one form of IPV (aOR=1.88; 95\% CI 1.52 to 2.31).

Table 3 also shows sensitivity analysis using two subsets of studies: those with volunteer recruitment into the trial and those with household-level recruitment. The pooled point estimate for the association between disability and physical IPV was higher in the study group with household-level recruitment OR 2.05 (95\% CI 1.61 to 2.61) vs the volunteer groups aOR 1.60 (95\% CI 1.29 to 1.97 ), although the overlap in confidence intervals suggests this is not a statistically significant difference. The same pattern was seen for sexual IPV with the aOR 2.77 (95\% CI 1.45 to 4.58 ) for the household sample, vs aOR 1.51 (95\% CI 1.25 to 1.84) for the volunteers. A similar pattern was observed for emotional IPV although the differences were more modest, while the direction of difference was reversed for economic IPV. For emotional IPV the household-level recruited study group was aOR 1.94 (95\% CI 1.56 to 2.41 ) vs aOR 1.73 (95\% CI 1.24 to 2.40) in the volunteer group. For economic IPV the household-level recruited study group was aOR 1.55 (95\% CI 1.27 to 1.90 ) vs aOR 1.68 (95\% CI 1.216 to 2.44 ) in the volunteer group.

As further sensitivity analysis, calculations described in table 3 were repeated with further adjustment for available measures of education and food insecurity. This resulted in no significant changes in findings, with less than $10 \%$ attenuation in the point estimates for all pooled aORs of association between disability and IPV (online supplementary table S2), collectively suggesting that these variables were not strong confounders of the relationship between disability and IPV. ${ }^{32}$

Figure 1 graphically illustrates the study-specific and pooled aORs and $95 \%$ CIs for physical, sexual, emotional and economic IPV, as well as for physical and/or sexual IPV (panel 5) and any IPV (panel 6). For most measures, considerable heterogeneity is observed, and it can be clearly seen that the dataset from Ghana is a modest outlier for measures that include physical and/ or sexual IPV (Cochran's Q and I ${ }^{2}$ statistics for these associations, including the impact of omitting Ghana from the pooled estimation, are provided in the online supplementary table 1). Only the smallest Sammanit Jeevan study $(n=200)$ shows no significant associations between disability and IPV. However, apart from economic IPV, the direction of association in this small study is consistent with other study-specific estimates, and the findings from the larger, household-based Nepali study Change Starts at Home $(n=1800)$ are entirely consistent with the other settings analysed.

The risk of experiencing all four forms of IPV, whether examined separately or combined, increased with increasing the severity of women's disability (table 4). In the studies with volunteer samples, the pattern was less 


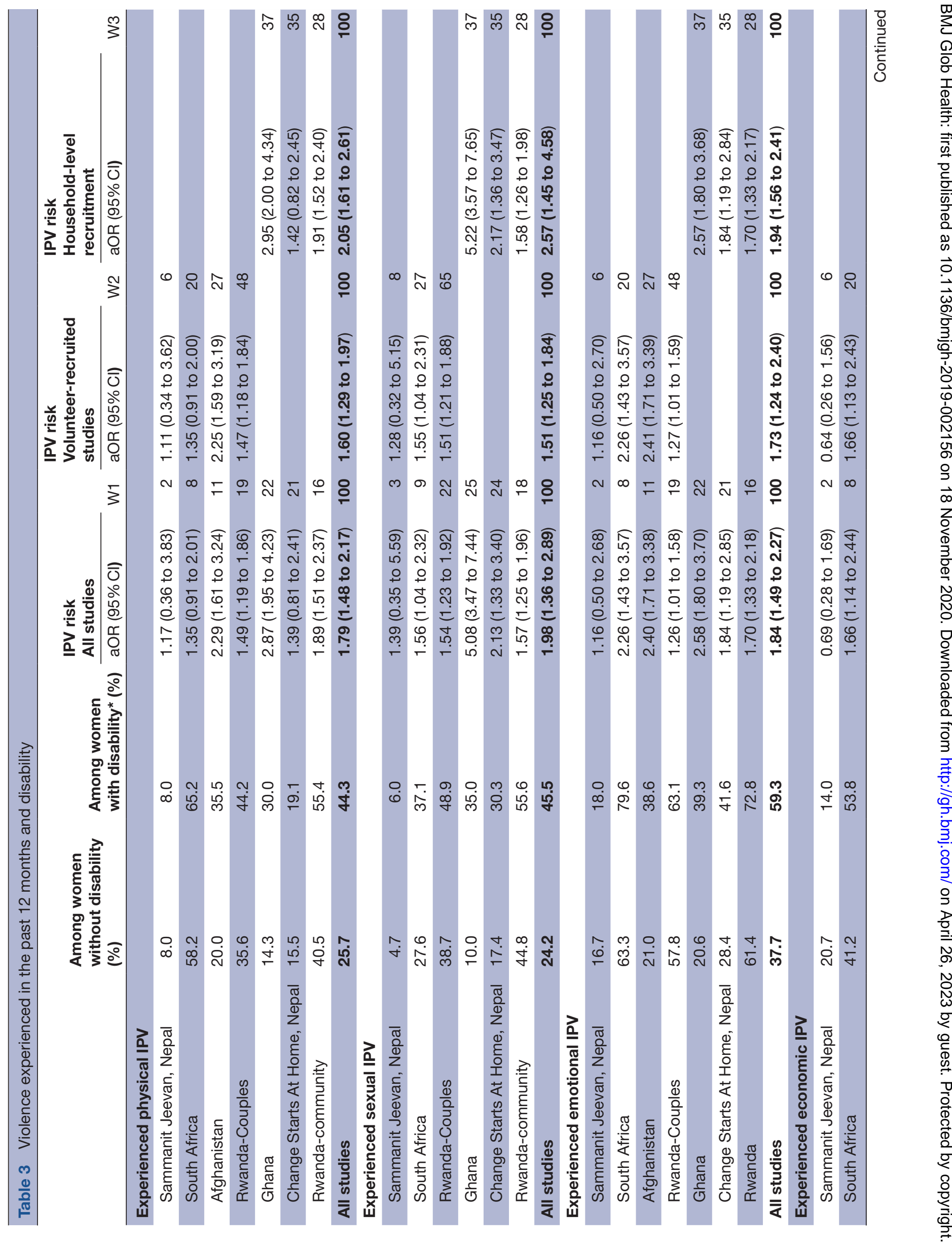



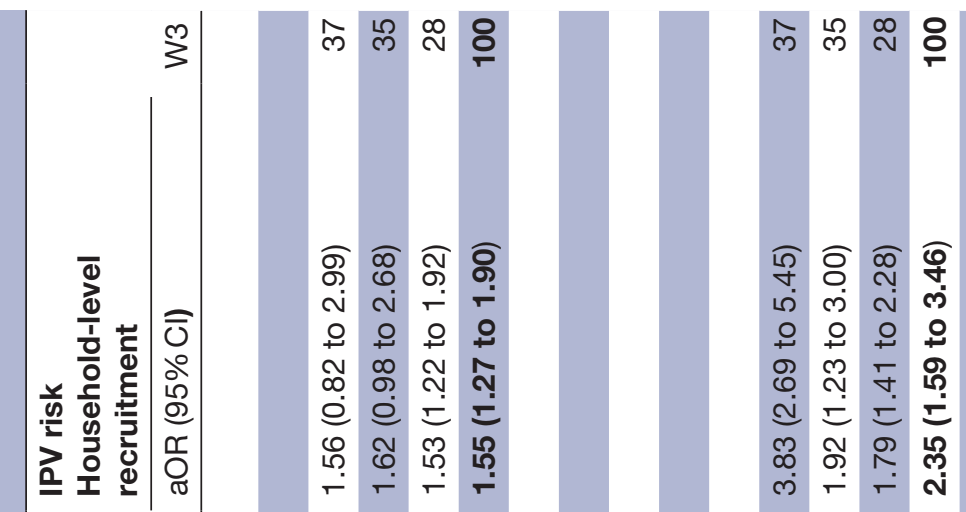

m

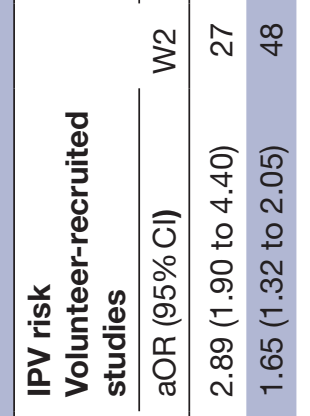

๑ ิำ

న

\& ลิ

ส ले तं

웅ㅇ 우

ำ จ กิ

E $\quad$ อ

ֻ

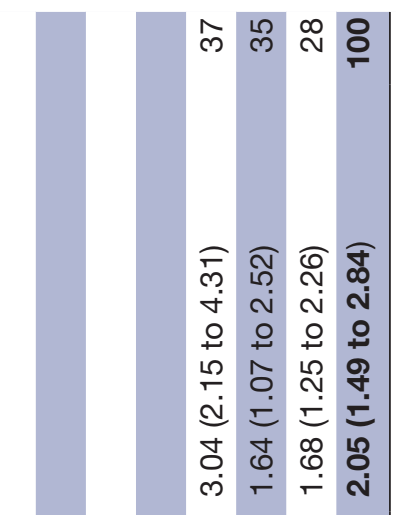

§ 든ำ

N $\infty$ 워

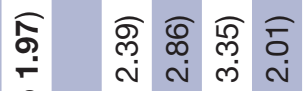

으 오 ำ

우

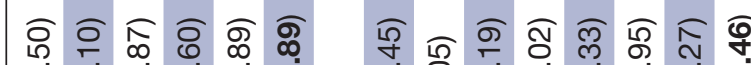

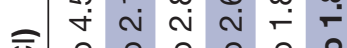

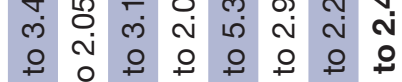

우웅ㅇ

ำ กิ

E

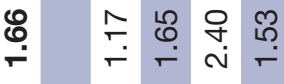

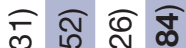

ช N $\mathrm{N}$ ก

웅ㅇㅇํ

४

우오 오 오 오웅

$\sim \infty \mp \stackrel{\leftarrow}{\sim} \overline{\mathrm{N}} \stackrel{\circ}{\circ}$

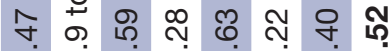

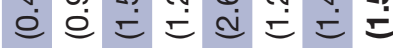

ब্ল

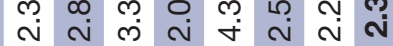

웅ㅇㅇㅇㅇㅇㅇㅇㅇ

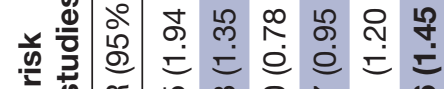

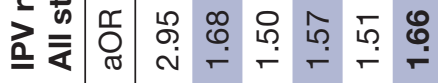

స়

กิ่

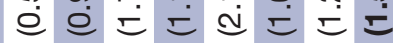

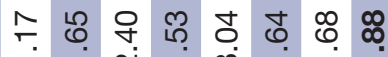

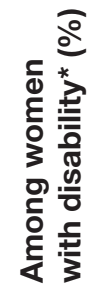

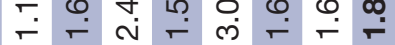

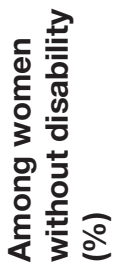

$\infty$ ㄴ

กิ่

ஸे

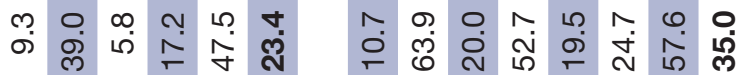

ヘุ

$\frac{\bar{\alpha}}{2}$

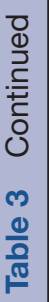

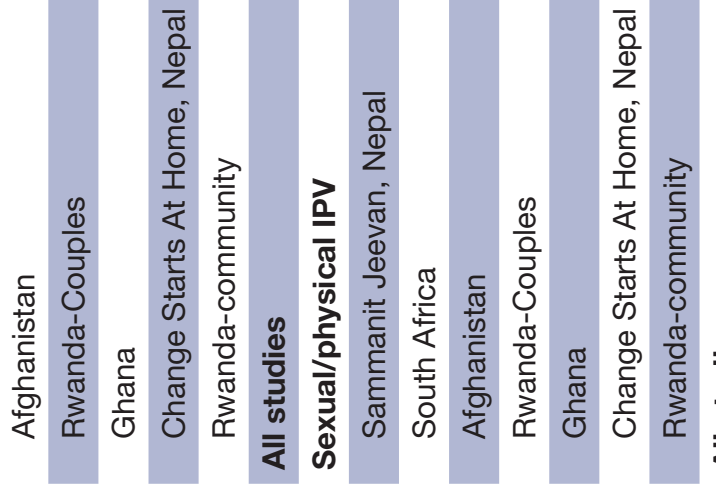

बळ

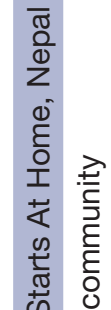




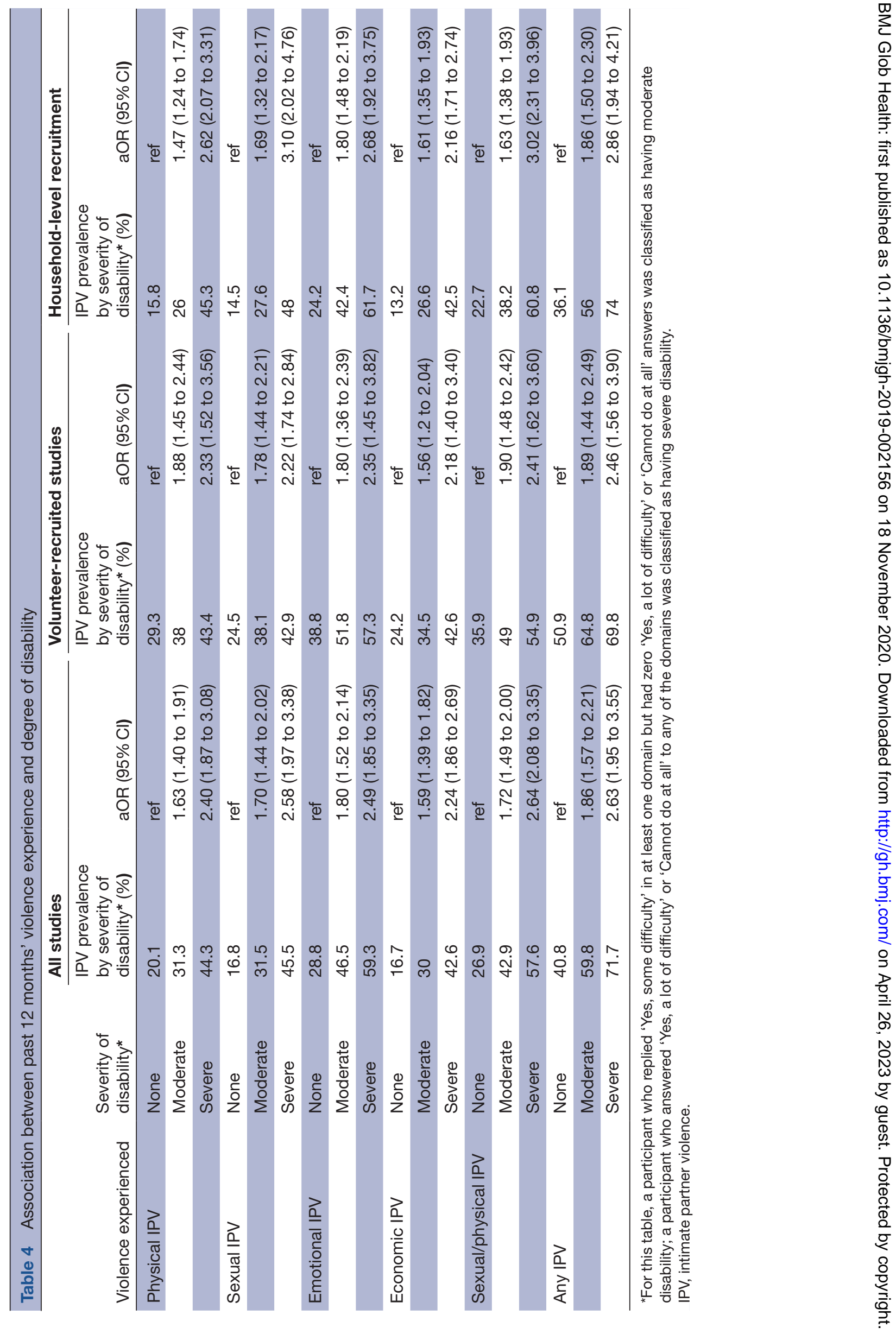


clear, with little difference in effect size by violence severity for physical and sexual IPV, and sexual IPV associations did not show a dose response relationship with severity of disability. In the studies with household recruitment, the dose-response pattern was seen with all measures of violence and the effect was statistically significant for physical and sexual IPV. As above, all analyses described in table 4 were repeated with further adjustment for available measures of education and food insecurity. This again resulted in less than $10 \%$ attenuation in the point estimates for aORs of association between disability and IPV (online supplementary table S3), affirming that the association between severity of disability and increasing risk of IPV is not meaningfully confounded by these variables.

\section{DISCUSSION}

This pooled analysis of data from seven studies in five countries shows that there is nearly a twofold increased risk of past 12 months' experience of IPV among women with disability compared to those without disability. This association is consistent across different types of IPV, as well as combined measures of IPV. We have also shown that the association between past 12 months' IPV and disability strengthens with increasing severity of disability. These findings indicate that women with disabilities across diverse cultural contexts in the Global South are at increased risk of experiencing IPV.

Our findings respond to the call in previous literature for examining the association between disability and IPV across settings using consistent strategies to measure both disability and IPV, ${ }^{11}$ and to the urgent need to explore these associations in detail in low and middle income countries. ${ }^{11}$ These findings from diverse settings in the Global South echo a similar demonstration of increased risk of IPV among women with disability in the Global North ${ }^{11-18}$ and build on the limited research on this topic to date in the Global South. ${ }^{22-27}$ Our findings affirm that the increased occurrence of IPV among women with disability is a consistent global phenomenon, and strongly indicate that interventions seeking to assist women experiencing IPV in in low and middle income countries, or to identify groups at increased risk of IPV for prevention programming, need to accommodate the likelihood that an appreciable proportion of the target population will have a disability.

A unique contribution of our analysis is the demonstration that the association between disability and risk of IPV increases with increasing severity of disability. We demonstrated that not only are women with moderate levels of disability at increased risk of IPV compared to those reporting no disability, but women with severe disability are in most cases at greater risk of IPV than those with only moderate disability. This trend of increasing risk of IPV associated with increasing severity of disability held across multiple dimensions of IPV including physical, sexual, emotional, economic and an overall measure of any IPV. These findings are an urgent call for policy and decision-makers aiming to respond to, or prevent, IPV that their services must be made as accessible as possible to women with a wide range of disabilities, and equally that services for people with disabilities must be equipped to respond to IPV. Greater cooperation and sharing of expertise and best practices between women's organisations and disabled people's organisations is unquestionably warranted.

The findings presented here are consistent across geographical settings and a range of sensitivity analyses. Of the seven studies included, only the smallest, Sammanit Jeevan in Nepal, showed any points estimates below 1.00 (in two models out of six). This study's design was an outlier among those presented here in several respects: it had the smallest sample size $(n=200)$, widest age range (18 to 87 ), lowest prevalence of physical/sexual IPV $(11.0 \%)$ and is among the studies with high disability prevalence $(25.0 \%)$, in part related to the older age of some participants. Interestingly, our analysis of heterogeneity of the estimates (online supplementary table S1) showed that Ghana was the most numerically significant outlier, with the highest estimated aOR for the association between disability and IPV. Nevertheless, the conclusions from our pooled models remain the same if either Nepal or Ghana is excluded from the pooled analysis (data not shown). Further confidence in the conclusion of a strong association between disability and IPV lies in the fact that when we split the pooled analysis into volunteer samples (less representative) vs household surveys (more representative), the more representative household surveys yield higher points estimates for the association between disability and recent IPV. Finally, testing possible sociodemographic confounding variables (education and food insecurity) in the models yields no changes in statistical significance and less than a $10 \%$ change in any point estimates of the association. We conclude that our findings are robust and coherent across a range of analytic approaches, which lends considerable confidence to our fundamental conclusions of a strong association between disability and recent experience of IPV, as well as the conclusion that more severe disability is associated with increased likelihood of reporting recent IPV.

\section{Strengths and limitations}

The main strength of this study lies in the synthesis of data from multiple countries with considerable consistency in the measurement of both past 12 months' experience of IPV and current disability status, both of which were assessed using measures specifically designed to generate estimates that could be compared across different countries. ${ }^{30}$ This results in an ability to compare findings across settings that has so far been lacking in research on associations between disability an IPV in the Global South. However, there were some minor differences in the lists of questions used between studies, resulting from the need to tailor surveys to specific settings and specific programmes. In addition, the WG-SS of questions are 
limited in their ability to capture disabilities related to mental health conditions or chronic illness. ${ }^{34}$ We recognise that some women with disabilities will have been classified as non-disabled as a result of these limitations. Likewise, the unevenness in measures of economic and emotional IPV and the absence of a sexual IPV measure in Afghanistan will have misclassified some women as not experiencing recent IPV. All measures of disability and recent experience of IPV relied on self-report, and are therefore likely to be underestimated due to disclosure bias. The collective result of these under-estimates, however, would likely be to bias our findings toward the null. A further limitation of this analysis was our inability to fully include potentially important covariates such as education, poverty and employment due to contextual differences in how these were assessed across settings. Where future research on this topic takes place with more homogenous study populations, it will be valuable to explore how the association between disability and IPV may be mediated or moderated by such factors, to help inform effective prevention of and response to IPV among women with disabilities.

This research was cross-sectional and so we cannot draw conclusions about the extent to which the measured associations reflect an increased risk of IPV among women with disabilities vs the extent to which reported disabilities may reflect the consequences of IPV. It is likely that both of these pertain to varying extents. In using a measure of past 12 months' exposure to IPV, we have tried to contemporaneously link disability with exposure to violence, but it is still not possible to determine which preceded the other without information on when the disability was acquired. These temporal directions of these relationships will need to be further elucidated through more detailed, and ideally longitudinal, research.

All studies included here had explicit inclusion criteria around the ability to both consent to and participate in research interviews that led to the exclusion of women with certain physical disabilities, as well as those with intellectual disabilities. We note, therefore, that none of the estimates here can be fully extrapolated to the general population. This is a limitation that should be addressed in future research.

\section{CONCLUSION}

IPV prevention and response programmes in the Global South must become more skilful in explicit outreach to and inclusion of women with disabilities, and ensure that communication channels, venues, programme materials and activities are developed with maximum accessibility in mind. Partnerships with, and visible leadership from women with disabilities and disabled people's organisation will be essential to ensure skilled and inclusive programmatic responses to address IPV among women with disabilities. While all women included in projects reported here were physically and cognitively able to participate in research interviews, it seems highly likely that the association between increasing severity of disability and increasing vulnerability to IPV would extend to women with more severe disabilities. This will be an essential question to address in future research and intervention work, and will likely require further advances in data collection techniques and development of appropriate guidelines on safety and ethics for researchers and programme planners.

Acknowledgements The authors wish to thank the research teams, programme staff and participants from all studies included in this analysis.

Contributors EC co-conceptualised the paper, led the data analysis, participated in interpretation of the findings and co-wrote the manuscript. RJ obtained the funding and directed the What Works Global Programme, co-conceptualised this paper and contributed to the data analysis, interpretation of the findings and preparation of the manuscript. IVDH led the literature review, participated in interpretation of the findings and co-wrote the manuscript. KD co-conceptualised the paper, oversaw and participated in the data analysis, led interpretation of the findings and co-wrote the manuscript. All authors read and approved the final manuscript.

Funding All studies presented, as well as this pooled analysis of the data, were funded through the What Works To Prevent Violence? A Global Programme on Violence Against Women and Girls (VAWG) funded by the UK Government's Department for International Development (DFID). However, the views expressed do not necessarily reflect the department's official policies and the funders had no role in study design; collection, management, analysis and interpretation of data; writing of the report; or the decision to submit the paper for publication. Funding was managed by the South African Medical Research Council.

\section{Competing interests None declared.}

Patient and public involvement Patients and/or the public were not involved in the design, or conduct, or reporting, or dissemination plans of this research.

\section{Patient consent for publication Not required}

Ethics approval All studies received approval from appropriate ethical review boards affiliated with the study sites and researcher institutions; the Rwandan research was additionally approved by the National Institute of Statistics Rwanda.

Provenance and peer review Not commissioned; externally peer reviewed.

Data availability statement De-identified individual participant data for Sammanit Jeevan (Nepal), Stepping Stones and Creating Futures (South Africa), Women for Women International (Afghanistan), Evaluation of the Rural Response System (Ghana), and Change Starts at Home (Nepal) are available to anyone who wishes to access the data for any purpose at http://medat.samrc.ac.za/index. php/catalog/WW. De-identified individual participant data from the Indashyikirwa couples cohort and community surveys (Rwanda) are available from the corresponding author, but may require permission from the Rwandan Ministry of Gender and Family Promotion (MIGEPROF) before transfer.

Open access This is an open access article distributed in accordance with the Creative Commons Attribution Non Commercial (CC BY-NC 4.0) license, which permits others to distribute, remix, adapt, build upon this work non-commercially, and license their derivative works on different terms, provided the original work is properly cited, appropriate credit is given, any changes made indicated, and the use is non-commercial. See: http://creativecommons.org/licenses/by-nc/4.0/.

ORCID iD

Kristin Dunkle http://orcid.org/0000-0003-3071-5544

\section{REFERENCES}

1 Devries KM, Mak JYT, García-Moreno C, et al. Global health. the global prevalence of intimate partner violence against women. Science 2013;340:1527-8.

2 Ellsberg M, Jansen HAFM, Heise L, et al. Intimate partner violence and women's physical and mental health in the who multi-country study on women's health and domestic violence: an observational study. Lancet 2008;371:1165-72.

3 Thomas KA, Joshi M, Wittenberg E, et al. Intersections of harm and health: a qualitative study of intimate partner violence in women's lives. Violence Against Women 2008;14:1252-73. 
4 Garcia-Moreno C, Jansen HAFM, Ellsberg M, et al. Prevalence of intimate partner violence: findings from the who multi-country study on women's health and domestic violence. Lancet 2006;368:1260-9.

5 Campbell JC. Health consequences of intimate partner violence. Lancet 2002;359:1331-6.

6 World Health Organization, World Bank. World report on disability 2011, 2011. Available: https://apps.who.int/iris/handle/10665/44575

7 Saxton M, Curry MANN, Powers LE, et al. "Bring My Scooter So I Can Leave You". Violence Against Women 2001;7:393-417.

8 Nosek MA, Foley CC, Hughes RB, et al. Vulnerabilities for abuse among women with disabilities. Sex Disabil 2001;19:177-89.

9 Jewkes R, Fulu E, Tabassam Naved R, et al. Women's and men's reports of past-year prevalence of intimate partner violence and rape and women's risk factors for intimate partner violence: a multicountry cross-sectional study in Asia and the Pacific. PLoS Med 2017;14:e1002381.

10 Stöckl H, March L, Pallitto C, et al. Intimate partner violence among adolescents and young women: prevalence and associated factors in nine countries: a cross-sectional study. BMC Public Health 2014:14:751.

11 Hughes K, Bellis MA, Jones L, et al. Prevalence and risk of violence against adults with disabilities: a systematic review and metaanalysis of observational studies. Lancet 2012;379:1621-9.

12 Hahn JW, McCormick MC, Silverman JG, et al. Examining the impact of disability status on intimate partner violence victimization in a population sample. J Interpers Violence 2014;29:3063-85.

13 Schröttle M, Glammeier S. Intimate partner violence against disabled women as a part of widespread victimization and discrimination over the lifetime: evidence from a German representative study. International Journal of Conflict and Violence 2013;7:232-48.

14 Scherer HL, Snyder JA, Fisher BS. Intimate partner victimization among college students with and without disabilities: prevalence of and relationship to emotional well-being. $J$ Interpers Violence 2016;31:49-80.

15 Breiding MJ, Armour BS. The association between disability and intimate partner violence in the United States. Ann Epidemiol 2015;25:455-7.

16 Smith DL. Disability, gender and intimate partner violence: relationships from the behavioral risk factor surveillance system. Sex Disabil 2008;26:15-28.

17 Brownridge DA. Partner violence against women with disabilities: prevalence, risk, and explanations. Violence Against Women 2006;12:805-22.

18 Basile KC, Breiding MJ, Smith SG. Disability and risk of recent sexual violence in the United States. Am J Public Health 2016;106:928-33

19 Krnjacki L, Emerson E, Llewellyn G, et al. Prevalence and risk of violence against people with and without disabilities: findings from an Australian population-based study. Aust N Z J Public Health 2016;40:16-21.

20 Hughes B, McKie L, Hopkins D, et al. Love's Labours Lost? Feminism, the Disabled People's Movement and an Ethic of Care. Sociology 2005;39:259-75.

21 Mitra S, Posarac A, Vick B. Disability and poverty in developing countries: a multidimensional study. World Dev 2013;41:1-18.

22 Hasan T, Muhaddes T, Camellia S, et al. Prevalence and experiences of intimate partner violence against women with disabilities in Bangladesh: results of an explanatory sequential mixed-method study. J Interpers Violence 2014;29:3105-26.

23 Puri M, Misra G, Hawkes S. Hidden voices: prevalence and risk factors for violence against women with disabilities in Nepal. BMC Public Health 2015;15:261.

24 Astbury J, Walji F. The prevalence and psychological costs of household violence by family members against women with disabilities in Cambodia. J Interpers Violence 2014;29:3127-49.
25 Valentine A, Akobirshoev I, Mitra M. Intimate partner violence among women with disabilities in Uganda. Int J Environ Res Public Health 2019;16. doi:10.3390/ijerph16060947. [Epub ahead of print: 16 Mar 2019].

26 Gibbs A, Carpenter B, Crankshaw T, et al. Prevalence and factors associated with recent intimate partner violence and relationships between disability and depression in post-partum women in one clinic in eThekwini Municipality, South Africa. PLoS One 2017;12:e0181236.

27 Gupta J, Cardoso LF, Ferguson G, et al. Disability status, intimate partner violence and perceived social support among married women in three districts of the Terai region of Nepal. BMJ Glob Health 2018;3:e000934.

28 Madans JH, Loeb M. Methods to improve international comparability of census and survey measures of disability. Disabil Rehabil 2013;35:1070-3.

29 Washington Group on Disability Statistics. WG Document \#5AAnalytic Guidelines for the Washington Group Short Set - SPSS, 2019. Available: http://www.washingtongroup-disability.com/wpcontent/uploads/2016/12/WG-Document-5A-Analytic-Guidelinesfor-the-Washington-Group-Short-Set-SPSS.pdf [Accessed $30 \mathrm{Sep}$ 2019].

30 Garcia-Moreno C, Jansen HA, Ellsberg M, et al. Who Multi-Country study on womens health and domestic violence against women. Geneva: World Health Organization, 2005.

31 Kontopantelis E. A comparison of one-stage vs two-stage individual patient data meta-analysis methods: a simulation study. Res Synth Methods 2018;9:417-30.

32 Rothman KJ, Greenland S, Lash TL. Modern epidemiology. Philadelphia: Lippincott Williams \& Wilkins, 2012.

33 Madans $\mathrm{JH}$, Loeb ME, Altman BM. Measuring disability and monitoring the un convention on the rights of persons with disabilities: the work of the Washington group on disability statistics. BMC Public Health 2011:11 Suppl 4:S4.

34 Sabariego C, Oberhauser C, Posarac A, et al. Measuring disability: comparing the impact of two data collection approaches on disability rates. Int J Environ Res Public Health 2015;12:10329-51.

35 Shai N, Pradhan GD, Chirwa E, et al. Factors associated with IPV victimisation of women and perpetration by men in migrant communities of Nepal. PLoS One 2019;14:e0210258.

36 Gibbs A, Washington L, Willan S, et al. The stepping stones and creating futures intervention to prevent intimate partner violence and HIV-risk behaviours in Durban, South Africa: study protocol for a cluster randomized control trial, and baseline characteristics. BMC Public Health 2017;17:336.

37 Gibbs A, Corboz J, Jewkes R. Factors associated with recent intimate partner violence experience amongst currently married women in Afghanistan and health impacts of IPV: a cross sectional study. BMC Public Health 2018;18:593.

38 Stern E, Martins S, Stefanik L, et al. Lessons learned from implementing Indashyikirwa in Rwanda- an adaptation of the Sasa! approach to prevent and respond to intimate partner violence. Eval Program Plann 2018;71:58-67.

39 Dunkle K, Stern E, Chatterji S, et al. Effective prevention of intimate partner violence in Rwanda through a couples training programme: results from the Indashyikirwa community randomized controlled trial. BMJ Global Health 2020.

40 Ogum Alangea D, Addo-Lartey AA, Sikweyiya Y, et al. Prevalence and risk factors of intimate partner violence among women in four districts of the central region of Ghana: baseline findings from a cluster randomised controlled trial. PLoS One 2018;13:e0200874.

41 Clark CJ, Spencer RA, Shrestha B, et al. Evaluating a multicomponent social behaviour change communication strategy to reduce intimate partner violence among married couples: study protocol for a cluster randomized trial in Nepal. BMC Public Health $2017 ; 17: 75$ 